\title{
Learning with Abductive-Pictorial Strategy for Improving Mathematical Proofing Ability of Prospective Mathematics Teachers
}

\author{
Ahmad Muzaki ${ }^{1}$, Yaya $S . K^{2}$, Jozua $S^{3}$ \\ ${ }^{1}$ Doctoral Student of Mathematics Education, Universitas Pendidikan Indonesia, Jln. Dr. \\ Setiabudi No. 229, Bandung 40154, Indonesia. \\ ${ }^{2}$ Lecturer of Mathematics Education, Universitas Pendidikan Indonesia, Jln. Dr. Setiabudi No. \\ 229, Bandung 40154, Indonesia. \\ ${ }^{3}$ Lecturer of Mathematics Education, Universitas Pendidikan Indonesia, Jln. Dr. Setiabudi No. \\ 229, Bandung 40154, Indonesia. \\ zackyborju@gmail.com
}

\begin{abstract}
This study aims to improve the mathematical proofing ability of prospective mathematics teachers in IKIP Mataram using Abductive - Pictorial Strategy (which will be abbreviated as APS). This study used an explanatory sequential design, a combination of quantitative and qualitative methods in sequence. The first stage is done by quantitative method and the second stage with qualitative method. Quantitative method is used to obtain measurable data and qualitative method is used to explore the findings obtained from the quantitative stage. This research considers the Prior Mathematical Knowledge (PMK) factor of prospective teacher. The results showed that the improvement of students' mathematical proofing ability in high, medium, and low PMK categories with APS better than Conventional Learning (CL). The mean improvement of students' mathematical proofing ability in high PMK category which got learning with APS and PK included in medium category. The mean improvement of students' mathematical proofing ability in medium PMK category with APS included in medium category, with CL included in low category. The mean improvement of students' mathematical proofing ability in the low PMK category with APS and CL included in low category.
\end{abstract}

Keyword : Abductive-Pictorial Strategy, Prior Mathematical Knowledge, improvement, Mathematical proofing ability.

\section{Background}

Based on the research conducted by Muzaki (2012) on number theory, the difficulties experienced by students in the proofing are as follows. 


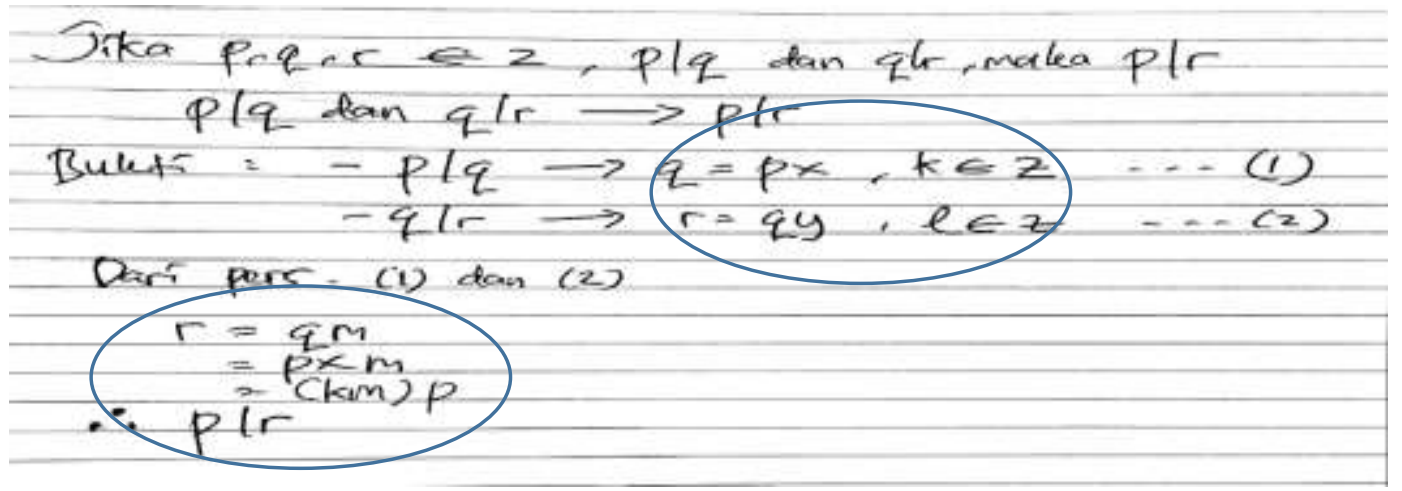

Figure 1 The results of student's work

Figure 1 is the result of student's work. From reading difficulty and constructing proof indicators, students still tend to follow the steps of previous proofing without understanding the definition contained in a problem. In addition, the students were still unable to use the definition to construct the proof.

This is similar to Moore's research (1994) to identify students' difficulties in drawing up proof, among others due to: (1) students cannot understand and state the definition; (2) students have limited intuition related to concept; (3) the concepts possessed by the student are not sufficient to establish a proof; (4) students are unable to build their own example to clarify the proof; (5) the students do not know how to use the definition to compile the complete proof; (6) students do not understand the use of language and mathematical notation; and (7) students do not know how to start the proofing.

The importance of proofing is also confirmed by Waring (Chambers, 2009) that learning of proofing needs to be included in the national curriculum. Through the discussion of proofing, students gain a deep understanding of mathematical concepts. Further, Waring's statement (Chambers, 2009) that learning of proofing is one alternative approach to teaching mathematics. In addition, Hanna (2010) also states that writing a mathematical proofing will help students understand the subject being studied.

According to Senk's (Hanna and Jahnke, 1996) research on the ability of writing proofs of 1520 high school students on Euclid's geometry lessons, only 30\% of these students reached the mastery level of writing proof. Based on the research of Isnarto (2011), the difficulty in constructing the proof could be influenced by the level of student maturity. Samparadja (2014) states that the low proofing ability of students is influenced by the approach and understanding of the definitions and interpretations of the symbols displayed explicitly in the definitions and theorems. The focus of mathematical maturity of students is the ability to read and write mathematics material and the ability to learn mathematics using the various resources available.

Based on the above description, the process of teaching and learning mathematics needed a learning innovation to develop the ability of mathematical proofing. One way is to apply the learning Abductive-Pictorial Strategy. Abductive is a mathematical thinking ability that does not fully answer a problem but it is a process of offering reasons as the basis for a particular action (Aliseda, 2007). In addition, Abductive strategies can lead students to identify the facts given (data) and formulate the facts 
asked in the problem (final target) (Toulmin, 2003). In determining the final target based on existing data, it is necessary to elaborate skills by applying the relevant essential concepts to the data provided to obtain intermediate targets before finding the answer of the final target. This process is not easy, so it takes a scaffolding in the form of a concrete illustration to the final target that is more abstract (Riccomini, 2010). Therefore, in this research, abductive strategy is combined with concrete pictorial abstract strategy in order to help students to improve the ability of mathematical posing problem.

The student's Prior Mathematical Knowledge (PMK) plays a very important role. Ruseffendi (in Hamid, 2015) states that from a group of students who are not specifically chosen (arbitrary), we will always encounter students whose abilities are low, medium and high, because students' abilities (including math skills) spread normally. This means that the heterogeneous initial ability of the student will contribute to improving students' mathematical proofing ability.

Based on the above description, this study discuss as the improvement of mathematical proofing ability of students who gain learning with abductive- pictorial strategy and who obtain conventional learning viewed from student's prior mathematical knowledge (PMK) factor.

\section{Research Methods}

This study used an explanatory sequential design that is a combination of quantitative and qualitative methods in sequence (Creswell, 2010). The first stage were done by quantitative method and the second stage with qualitative method. Quantitative methods were used to obtain measurable data and qualitative methods were used to explore the findings obtained from the quantitative phase. The research implementation scheme used is presented in Figure 2.

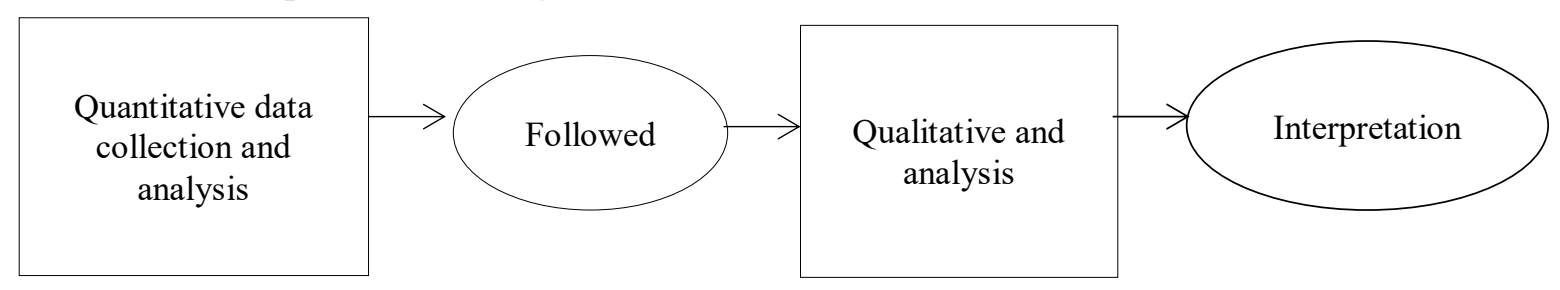

Figure 2. Research design explanatory sequential type

The research design in the quantitative phase used a quasi experimental design in the form of non equivalent control group design. In quasi experiments, subjects are not randomly grouped purely (Ruseffendi, 2010). The research design is described as follows:

Experiment group

Control group

Information:

$\mathrm{O}=$ Pre-test and post-test the ability of mathematical proofing.

$X=$ The treatment of learning with APS. 
This second phase of research used a grounded theory approach that is the development of theory based on data obtained systematically and analyzed in the framework of social research (Creswell, 2010). The grounded theory approach is a qualitative research method that used a number of systematic procedures to develop theories from the research scene. The grounded theory approach uses three steps in sequence, namely open coding, axial coding and selective coding.

Population in this research is all students at Department of Mathematics Education, IKIP Mataram in odd semester 2015/2016. The sample in this study were Class A and B in the Real Analysis II course. The number of samples for class A is 45 people and class $\mathrm{B}$ is 49 people. Class $\mathrm{A}$ is an experimental class that gets learning with abductive pictorial abstract (APS). While Class B is a control class that gets learning with convention learning (CL).

Sample selection technique in this research were done by Purposive Sampling. The used of this technique were done because the study group available for the Real Analysis I course consists of two classes. According to Ruseffendi (2010) the selection of purposive techniques on the basis of knowledge of researchers about the population, elements, and nature of research purposes. In other words that the researcher chooses the subject of this study is based on their knowledge and internal characteristics.

Before the learning begins, subjects are given pre-test and treatment in the form of learning with APS and then performed a post-test to measure the ability of mathematical proofing ability. The results of pre-test and post-test were then analyzed to obtain a normalized gain of $\langle\mathrm{g}\rangle$ as an increase in the ability of students' mathematical proofing ability.

\section{Results and Discussion}

This study discusses the improvement of students' mathematical proofing abilities by abductive- pictorial strategy. A more comprehensive assessment was conducted by involving prior mathematical knowledge (PMK) as a control variable in the study. PMK are grouped into three categories: high, medium and low category. PMK category is based on PMK test results. The factorial design of this research variable is presented in Table 1.

Table 1. Factorial design variable research

\begin{tabular}{lll}
\hline \multirow{2}{*}{ PMK category } & \multicolumn{2}{c}{ Student Mathematical Proof Ability } \\
\cline { 2 - 3 } & APS Learning & Conventional Learning \\
\hline High & 12 & 7 \\
Medium & 27 & 32 \\
Low & 6 & 10 \\
\hline
\end{tabular}

Note. APS $=$ Abductive-Pictorial Strategy

The indicators of mathematical proofing ability in this study can be seen in Table 2 . 
Table 2. Indicator of mathematical proofing ability

\begin{tabular}{ll}
\hline \multicolumn{1}{c}{ DIMENSIONS } & \multicolumn{1}{c}{ ASPECT AT MEASURED } \\
\hline & $\begin{array}{l}\text { Ability to identify the facts obtained from the statement and } \\
\text { determine the final target of the statement. }\end{array}$ \\
\hline & $\begin{array}{l}\text { Ability to apply the steps of the proof into other similar } \\
\text { statements. }\end{array}$ \\
\cline { 2 - 2 } Reading Proof & $\begin{array}{l}\text { The ability to use definitions as a basis in giving reasons for right } \\
\text { proof measures or improvement of symbols, narratives, premises } \\
\text { at the stage / step of proof is not appropriate. }\end{array}$ \\
\cline { 2 - 2 } The ability to examine a mathematical statement to determine the \\
truth or to indicate the error of the statement by using an counter \\
example.
\end{tabular}

Based on the results of the calculations performed on the mathematical proofing, obtained the average improvement of students' mathematical proofing abilities based on PMK category. For more details presented on the average bar chart below.

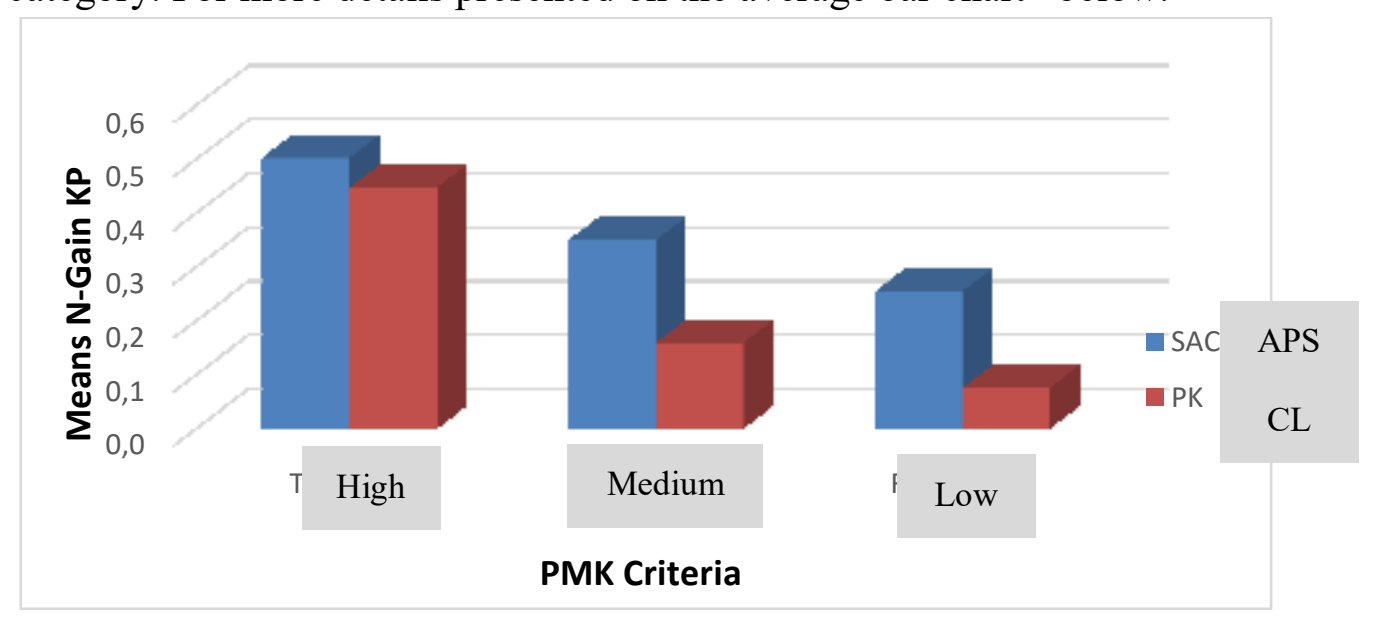

Figure 3. The mean improvement of mathematical proof ability

Based on Figure 3 and category of normalized gain (Hake, 1999), it is obvious that the mean improvement in mathematical proofing ability of students who obtained learning with APS in high PMK category higher than students who get PK. The mean of normalized gain categories that gained learning with APS and PK for high PMK was included in the medium level category. Furthermore, the mean improvement of mathematical proofing ability of students who obtained learning with APS in PMK 
category is higher than students who get PK. The mean of normalized gain learning with APS for PMK is included in the moderate level category. While the mean normalized gain rate that obtains learning with PK for PMK is included in low level category. The mean improvement of students' mathematical proof capability obtaining learning with APS in the low PMK category was lower than that of the PK students, although the average increase in the two groups viewed from the normalized gain was included in the low level category. In total, Fig. 2 shows that the mean improvement of students' mathematical proof of learning achievement with APS is higher than PK students, the categories of both groups increase from the normalized gain are included in medium category for high and medium PMK whereas for low PMK.

However, to show which improvement of proofing is better, it is necessary to test the average difference. Before performing the average difference test, the normality and homogeneity test of the variance of the two data sets to determine the appropriate statistical tests were performed. If the data are normally distributed and homogeneous, then t-test, non-distributed and homogeneous data are used non-parametric test is MannWhitney $U$ test. While normal distributed but not homogeneous data are used further test is T-test. The test criteria used in this study is $\mathrm{H}_{0}$ accepted if the probability value (sig.) Is greater than $\alpha=0.05$ and $\mathrm{H}_{0}$ is rejected if the probability value (sig.) is smaller than $\alpha=0.05$. The result of testing the difference of mean improvement of students' mathematical proof ability based on PMK category can be seen in Table 3 and Table 4.

Table 3. Test of Mean Difference of Increasing Student's Mathematical Proof Ability Based on PMK

\begin{tabular}{ccccc}
\hline $\begin{array}{c}\text { PMK } \\
\text { category }\end{array}$ & Learning & T-Test & Sig. (2-tailed) & Conclusion \\
\hline Low & APS: PK & 1.756 & 0.101 & $\mathrm{H}_{0}$ accepted \\
\hline
\end{tabular}

Table 4. Test of Difference Improvement of Student's Mathematical Proofing Ability Based on PMK

\begin{tabular}{|c|c|c|c|c|c|}
\hline $\begin{array}{l}\text { PMK } \\
\text { category }\end{array}$ & Learning & $\mathrm{N}$ & $\begin{array}{c}\text { Mann- } \\
\text { Whitney U } \\
\text { Test }\end{array}$ & Sig. (2-tailed) & Conclusion \\
\hline \multirow{2}{*}{ High } & SACPA & 12 & \multirow{2}{*}{29.000} & \multirow{2}{*}{0.257} & \multirow{2}{*}{$\mathrm{H}_{0}$ accepted } \\
\hline & PK & 7 & & & \\
\hline \multirow{2}{*}{ Medium } & SACPA & 27 & \multirow{2}{*}{230.000} & \multirow{2}{*}{0.002} & \multirow{2}{*}{$\mathrm{H}_{0}$ rejected } \\
\hline & PK & 32 & & & \\
\hline
\end{tabular}

Based on Table 3 it is clear that the average difference data of students' mathematical proof improvement in low PMK category with APS and PK learning has a probability value (sig) more than $\alpha=0.05$, this means $\mathrm{H}_{0}$ is accepted. So it can be concluded that the improvement of student's mathematical proof in the low PMK category with APS learning is the same as the improvement of students' mathematical proofing ability with PK learning.

Based on Table 4 the average difference data of students' mathematical proofing improvement in high PMK category has probability value (sig) more than $\alpha=0.05$, this 
means $\mathrm{H}_{0}$ is accepted. So it can be concluded that there is no difference of average improvement of students' mathematical proofing ability based on PMK category. While the average equality of the students' mathematical proof improvement in the PMK category is having a probability value (sig.) Less than $\alpha=0.05$, this means $\mathrm{H}_{0}$ is rejected. So it can be concluded that there is a difference of average improvement of students' mathematical proofing ability based on PMK category.

This shows that learning with APS has facilitated students well in terms of improving mathematical proofing ability. The description of several things that may affect the improvement of the mathematical proofing ability of students who obtained learning with APS is presented as follows.

Learning with abductive-pictorial strategy is a collaboration between abductive learning strategy and concrete-pictorial-abstract. Learning with APS is a learning that gives students the opportunity to explore their own abilities through the process of identifying the facts that are found leading to a conclusion. Abductive is a mathematical thinking ability that could not completely answer problems but is a process to offer reasons as the basis for certain actions. In addition to learning APS, lecturers provide scaffolding in the form of concrete illustrations in order to help students to solve problems. Learning APS can improve the ability to read evidence, such as students able to detail the attributes of the problem (what is known in the matter) and what is asked on the matter well. In addition, APS learning can improve the ability to construct and write evidence because learning with APS focuses on the process of identifying findings or problems that are then generalized to the conditions that must be had to lead to a conclusion.

\section{Conclusions and Recommendations}

In general, improvement of mathematical proofing ability of students who received learning with APS in high, medium and low PMK categories was better than those who received conventional learning (CL). The mean improvement of students' mathematical proofing ability in the high PMK category that learning with APS is better than the students who got the CL. The mean improvement of students' mathematical proofing ability in high PMK category which got learning with APS and CL included in medium category. The mean improvement of students' mathematical proofing ability in medium PMK category with APS included in medium category, while with CL included in the low category. The mean improvement of students' mathematical proofing ability in the low PMK category who received learning with APS and PK included in the low category.

Based on the above conclusions, learning with APS is feasible to be implemented as an alternative learning model in Real Analysis in mathematics education program.

\section{References}

[1] Aliseda, A. (2007). Abductive Reasoning: Challenges Ahead. Theoria. 60: 261270. 
[2] Chambers, P. (2009). Teaching Mathematics: Developing as a Reflective Secondary Teacher. London: SAGE Publication Ltd.

[3] Creswell, J.W. (2010). Educational Research: Planning, Conducting, Evaluating quantitative and qualitative Research. Fourth Edition. Boston: Pearson.

[4] Hake, R.R. 1999. Analyzing Change/Ghain Scores. [Online]. Tersedia: http://www.physics.indiana.edu/-sdi/analyzingchange-Gain.pdf. [Diakses 20 Mei 2014].

[5] Hamid, H. (2015). Membudayakan Penggunaan Argumen Informal Sebagai Bentuk Transisi ke Bukti Formal dalam Mengkonstruksi Bukti. Prosiding ASEAN Comparative Research Network (ACER-N). Penerbit: Fakultas Pascasarjana Universitas Pasundan Bandung.

[6] Hanna, G. et al. (2010). Explanation and Proof in Mathematics: Philosophical and Educational Perspectives. New York: Springer.

[7] Hanna, G., Jahnke, H. N. (1996). Proof and Application. Dalam Educational Studies in Mathematics [online]. Vol 24, pp. 421-438. Tersedia di: http://www.jstor. Org. [Diakses 5 Mei 20015].

[8] Isnarto, Wahyudin, Didi Suryadi \& Dahlan A. J. (2014). Students' proof ability: exploratory studies of abstract algebra course. International Journal of Education and Research. Vol. 2. No. 6:215-228.

[9] Moore, R.C. (1994). Making the Transition to Formal Proof. Educational Studies in Mathematics, 27: 249-266.

[10] Muzaki, A. 2012. Problem-Based Learning Melalui Belajar Kooperatif ThinkPair-Share untuk Meningkatkan PPMKhaman Materi Keterbagian Bilangan Bulat. (Pada Mahasiswa Semester IV G Pendidikan MatPMKtika IKIP Mataram). Tesis UM. Tidak Diterbitkan.

[11] Riccomini, P. J. (2010). “CRA Math Instruction: Systematically Connecting Concrete to Representation to Abstract: Makalah pada MTSS Symposium. Kansas.

[12] Ruseffendi, H.E.T. (2010). Dasar-Dasar Penelitian Pendidikan dan Bidang NonEksakta lainnya. Bandung: Tarsito.

[13] Samparadja H, Wahyudin, Suryadi, D \& Kartasasmita, G. B. (2014). The influence of inductive-deductive approach based on modified definition in algebra structure learning toward student's proving ability viewed based on college entrance track. International Journal of Education and Research. Vol. 2. No. 7: 239-248.

[14] Toulmin, S. E. (2003). The Uses of Arguments (Updated Edition). Cambridge: University Press. 